\title{
A permanent magnet assist, segmented rotor, switched reluctance drive for fault tolerant aerospace applications
}

\author{
S. Ullah 1 , S.P. McDonald 1 ,R. Martin 1 , M.Benarous 2 and G.J. Atkinson 1 \\ 1. School of Electrical and Electronic Engineering, Newcastle \\ University, NE1 7RU, UK.(e-mail: sana.ullah@ncl.ac.uk) \\ 2. UTC Aerospace, Wolverhampton, WV10 7EH, UK
}

\begin{abstract}
This paper presents the design, analysis, prototype and testing of a new fault tolerant electrical drive topology. The Segmented Rotor Switched Reluctance Machine (S-SRM) has been modified to include permanent magnet assist by placing magnets in the stator slot opening. This introduces a magnetic bias which extends the magnetic operating region of the machine and results in greater torque when compared to the conventional fault tolerant segmental rotor switched reluctance machine. This new torque dense, fault tolerant topology was investigated using 2D and 3DFE methods and a prototype machine built, tested and verified against the simulations. Experimental testing was carried out with and without the magnets to assess the effect of the PM assist on torque performance. Static tests were carried out to obtain the torque - flux linkage - angle waveforms and then this information used to tune a bespoke drive and test the system under dynamic conditions.

The superior fault tolerant performance of this PMA S-SRM topology is highlighted by measurements taken under phase open and short circuit fault conditions.

The tests show that this fault-tolerant topology not only meets the mass requirements of the aerospace application, set originally by a PMSM, but also, with the magnets now placed on the stator the rotational induced EMFs and associated short circuit currents during a fault are drastically reduced. Hence the fault tolerance of this topology is an improvement on the PMSM topology, and it will be of benefit to fault critical systems such as aerospace drives and actuators.
\end{abstract}

Index Terms-- Segmental rotor switched reluctance machine, Rotating electrical machines. Permanent magnet machines, Fault tolerance, More electric aircraft, Aerospace drives.

\section{NOMENCLATURE}

PM - Permanent Magnet

SRM - Switched Reluctance Machine

S-SRM -Segmental Rotor Switched Reluctance Machine

PMA -Permanent Magnet Assist

2D FE -Two-Dimensional Finite Element Analysis

3DFE -Three-Dimensional Finite Element Analysis

FE -Finite Element Analysis

PMSM - Permanent magnet synchronous machine

\section{INTRODUCTION}

N witched reluctance machines (SRM) offer a simple, low cost and robust structure which is suited to harsh operating conditions [1] making them a contender for many household, electric vehicle and aerospace applications [1,2]. One drawback of the SRM is low torque density compared to a permanent magnet (PM) machine Segmental rotor switched reluctance machines (S-SRM) offer greater torque density and come someway to bridging the differences. When compared to an SRM, their improved electromagnetic structure offers a $40 \%$ increase in torque for the same copper loss [3, 4]. Magnets have previously been inserted into the SRM stator core back to improve field weakening performance, this is however at the expense of a reduced constant torque, due to the magnets increasing the reluctance of the main flux path $[5,6]$.

In order to add a magnetic bias, yet avoid changing the reluctance of the magnetic circuit, permanent magnets have been inserted between the stator tooth tips and magnetized alternately in the circumferential direction. A segmented stator SRM with PM assist is shown in [7] and in [8] a more standard SRM topology is enhanced with PM assist, giving a $25 \%$ increase in torque capability when compared to the same without PM assist.

PM machines are the obvious choice for the "More electric aircraft" [9] because of their high torque density and efficiency [10-15]. However, during fault conditions, the drag torque can increase significantly which necessitates the overrating of the healthy power lane [16]. This can affect the overall performance of the machine especially in aerospace applications which require significant redundancy [17-21].

This paper takes the PM assist concept introduced in [7-8] and applies this to a fault tolerant, interleaved 2x3-phase topology. To further maximize torque capability a segmented rotor structure is used [3]. This paper discusses the design investigation, construction, static and dynamic analysis and fault tolerance of a 24-20 (24 stator teeth, 20 rotor poles) fault tolerant PMA S-SRM.

The machine described here is designed with aerospace fault tolerant applications in mind and compared against a fault tolerant PMSM used as a nose wheel actuator for an aircraft during landing, take off and taxiing. The paper explains the basic concept of the machine and the contribution of PM assistance in this fault tolerant segmented rotor SRM. The problem of PM demagnetization in the stator slot is explored and a design solution proposed. Experimental testing of the prototype machine is presented both with and without PM assist, to assess the impact of the magnets, and finally the fault tolerance of the drive is highlighted.

\section{CONCEPT OF THE PM ASSIST S-SRM}

The operating range of the SRM is generally limited to the first quadrant of the B-H curve. This range can be extended to the third quadrant through the addition of a small amount of magnetic material which serves to magnetically reverse-bias 
the stator core, as illustrated in Fig. 1. This can increase the coenergy and therefore the torque capability of a given machine.
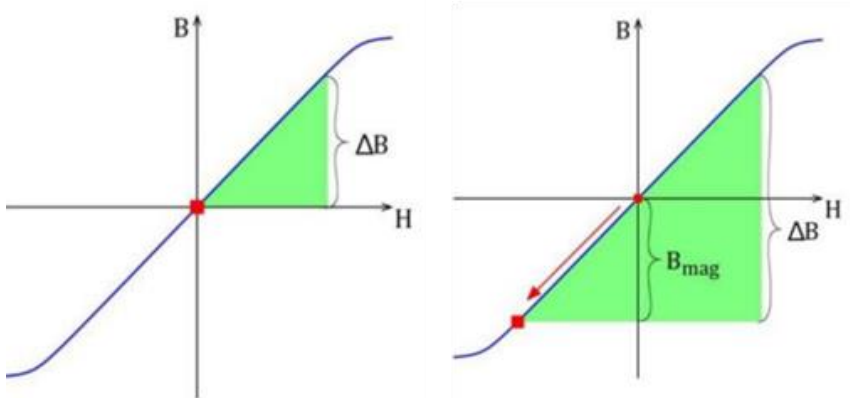

Fig. 1. Operating range of a standard SRM (left) Operating range of PM assisted SRM (right).

This concept is applied to an interleaved $2 \times 3$-phase fault tolerant stator, and coupled with a segmented rotor to maximize torque density for this aerospace application. Critically, the location of the PM assist improves the torque output of the S-SRM without compromising the inherent faulttolerant advantages of the SRM.

\section{THE APPLICATION, TOPOLOGY AND FAULT TOLERANCE}

This research formed part of the EU funded Actuation 2015 program [9]. The aim of this work was to replace an existing Permanent Magnet Synchronous Machine operating as an actuator for a nose wheel steering system with a Switched Reluctance equivalent.

Initial work concentrated on magnet free machines, in order to reduce costs and improve fault tolerance, but it became clear that the torque specification could not be met within the limited volume available. Hence some magnets were reintroduced. The machine and converter are designed to operate from a 540 VDC aircraft supply delivering $1.3 \mathrm{~kW}$ at $900 \mathrm{rpm}$ with a rated current of 11A (peak). A 24 slot, 20 pole topology has been developed. The prototype machine was designed to fit within a maximum volume and ensure a minimum standstill and average torque can be produced within the current limit shown in Table 1.

Table 1: Machine specifications
\begin{tabular}{|l|l|}
\hline Parameters & Dimensions \\
\hline Stator outer diameter & $230 \mathrm{~mm}$ \\
\hline Axial length & $30 \mathrm{~mm}$ \\
\hline Stator teeth & 24 \\
\hline Rotor poles & 20 \\
\hline Standstill-100 rpm torque & $17 \mathrm{Nm}$ \\
\hline Torque at base speed $(900 \mathrm{rpm})$ & $13 \mathrm{Nm}$ \\
\hline Peak current & $11 \mathrm{~A}$ \\
\hline
\end{tabular}

This machine is designed for an aerospace application, and as such fault tolerance is critical. The chosen topology is a twolane 3-phase structure [16] with one-lane in operation and one lane on standby. The concentrated windings for each lane are distributed around the periphery of the machine in an alternating manner to balance the thermal loading when any one lane is active. In Fig. 2, lane 1 is shown in blue and lane 2 in red.
The PM assist S-SRM topology is well suited to aerospace applications because of its inherent fault tolerance. The segmented rotor and coil arrangement minimize magnetic coupling between phases. The concentrated winding and spacer tooth structure provides electrical and thermal isolation between phases and power lanes. With the magnets having been removed from the rotor, problems associated with rotational induced voltages, fault currents and drag torque are eliminated, improving the fault tolerant capability of the actuator.

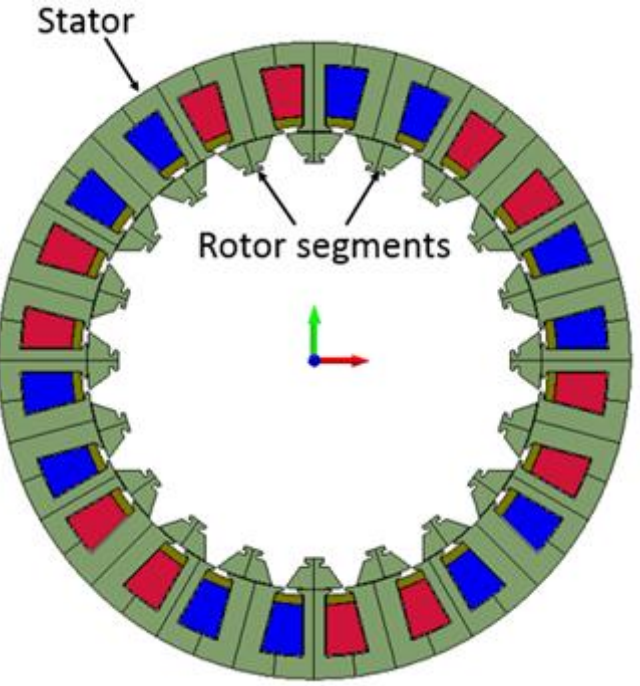

Fig. 2. Dual lane arrangement for the PM assist S-SRM. Lane 1 in red, lane 2 in Blue. Within a lane phases alternate A-B-C-A-B-C

\section{AVOIDING DEMAGNETISATION}

During development of the prototype a $29 \%$ increase in torque when compared to a conventional segmental rotor SRM was shown to be possible for the same copper loss [16]. However, the high current density and naturally cooled specification exposed the magnets to a rapid increase in the temperature during most severe fault condition (1.5 X rated current). The simulated magnet temperature rise during this fault is $200^{\circ} \mathrm{C}$ (SmCo magnets are used) and Finite Element Analysis (FE) was used to predict PM demagnetisation. Fig. 3 shows this topology and the predicted demagnetization under fault conditions. The blue area shows the safe area of the magnets whilst the red area shows the demagnetized region. It is clear that over $50 \%$ of the PM material becomes demagnetised. Demagnetisation is particularly apparent when the rotor is misaligned and the magnets experience a considerable reverse field.

In order to avoid demagnetization various magnet shapes and positions were investigated. The best performing solution found involves positioning the magnets higher in the slot, away from the stator tooth tips. Fig. 4 shows the resultant stator structure; this reduces the extent of demagnetization under the same conditions to $0.2 \%$ of the PM material.

The disadvantage of moving the magnets further into the slot is the reduction in winding area and commensurate reduction in MMF per slot at a fixed current density and fill factor. In order to achieve the specified torque, the stack length of this 
machine was increased by $25 \%$ when compared the PM, however it is shown later that the mass is comparable [22].
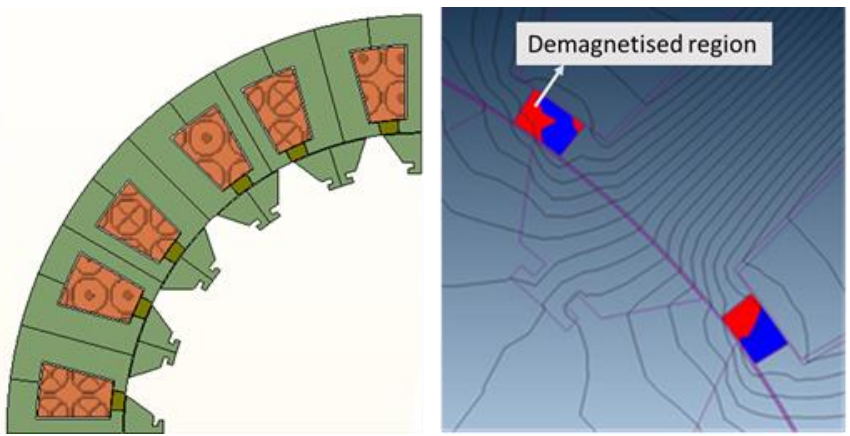

Fig. 3. PM-assisted S-SRM with magnets at the stator tooth tip (left) Demagnetisation prediction within the magnets at high temperature and under $1.5 \mathrm{X}$ rated current fault condition.
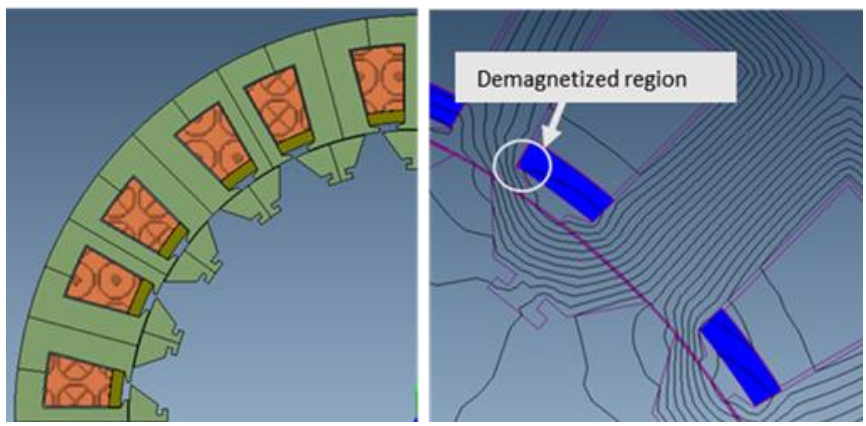

Fig. 4. PM-assisted S-SRM with magnets moved into the slot (left), Demagnetization within the magnet at high temperature during the $1.5 \mathrm{X}$ rated current fault condition.

\section{3DFE ANALYSIS OF TORQUE CAPABILITY}

The machine dimensions, set by the application, give a large aspect ratio $(230 \mathrm{~mm}$ outer diameter and $25 \mathrm{~mm}$ axial length). This results in a considerable end winding length, and hence significant end effects. Therefore 3DFE was required in order to include the end winding effect throughout the design development stage. The machine was modelled both with and without the magnets to assess the PM-assist effect. Fig. 5 shows the aligned and unaligned per-phase flux linkage both with and without PM assist. The PM assist characteristics have been normalized to zero flux linkage at zero current, for comparability. It is clear that the magnets have increased the enclosed area due to the delayed onset of magnetic saturation caused by reverse-bias of the magnets, and hence the total torque produced will be greater.

Throughout out the simulations the conduction angle is $180^{\circ}$. In Fig. 6 the torque capability with and without magnets is assessed. PM assist has increased the torque capability of the machine by $21 \%$ for the same phase current.

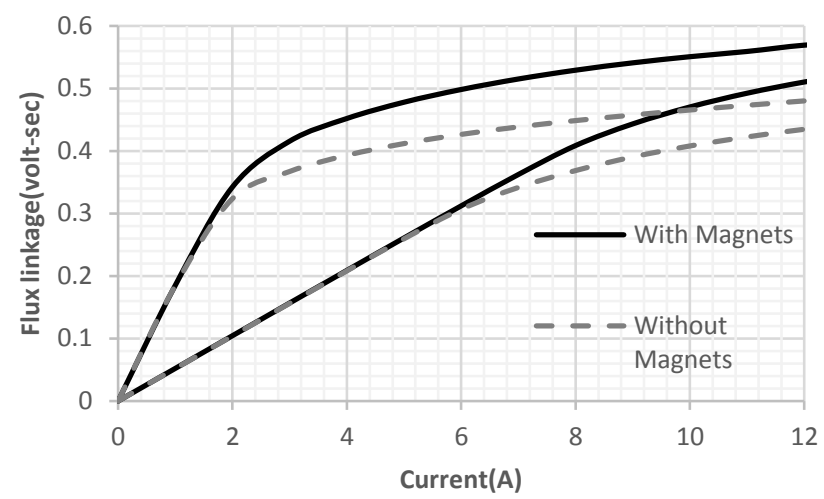

Fig. 5. Aligned and unaligned flux linkage curves with and without magnets (3DFE simulation).

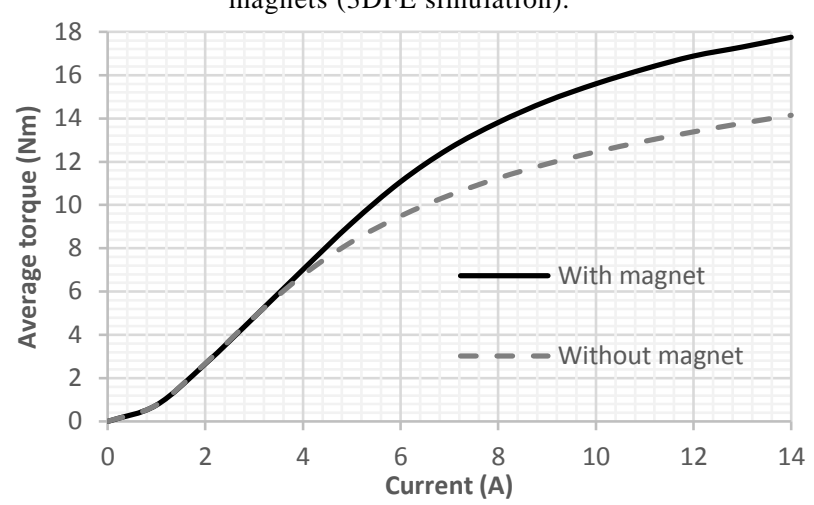

Fig. 6. Average torque with and without magnets (3DFE simulation).

\section{EXPERIMENTAL VERIFICATION}

A prototype fault-tolerant PMA S-SRM has been built and tested under static and dynamic conditions. Fig. 7 shows the static torque test rig with the machine while Fig. 8 shows a stator slot with the magnets indicated. Note the direction of magnetization is circumferential.

Flux linkage and static torque has been measured, and then in conjunction with its specifically designed controller and converter full dynamic testing has been carried out. A comparison with simulated results is given.

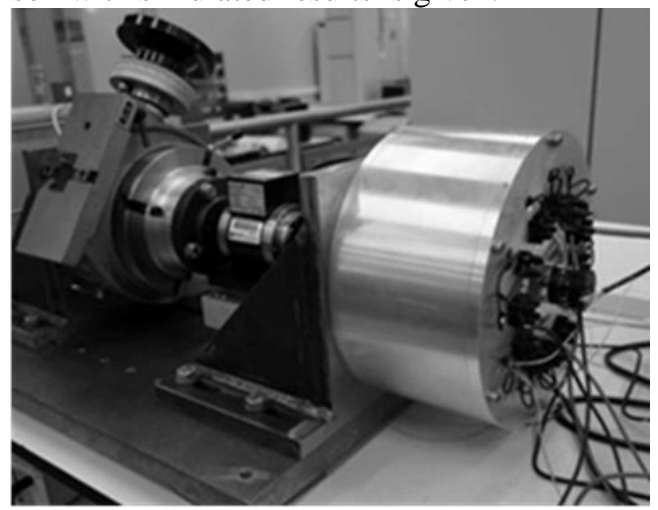

Fig. 7. Prototype PM assisted S-SRM under static testing. 


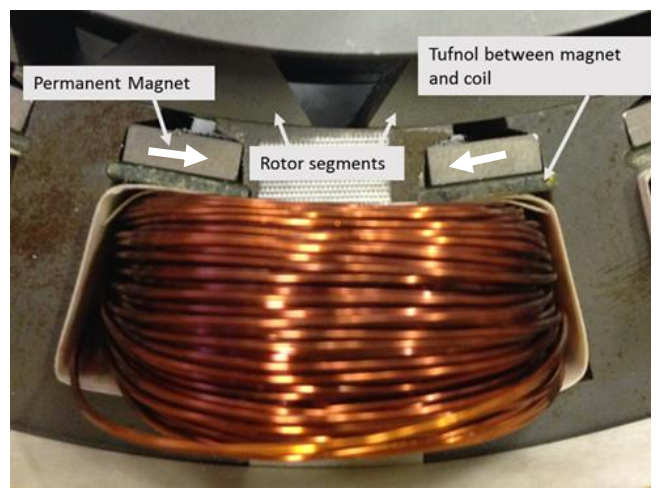

Fig. 8. Permanent magnets at the stator tooth tips. (magnetisation direction superimposed)

\section{A. Flux linkage ( $\Psi)$-current waveform}

By way of verification of the design procedure the $\Psi$-I data was measured and compared to the 3DFE result.

To obtain this data the rotor was rotated and the flux linkage of each phase at different positions obtained. A DC voltage was applied to each phase and the current monitored. Using equation 1 the flux linkage was calculated.

$$
\psi=\int_{o}^{t}[v-i R] d t
$$

Where $\Psi$ is the flux linkage, $\mathrm{R}$ is the resistance of each phase. From the full data set the fully aligned and fully unaligned curves were obtained. As shown Fig. 9, the experimental results compare very closely to the 3DFE results.

This procedure was then repeated after the magnets had been inserted into the stator, once again the experimental and simulated results match closely. When comparing the experimental $\Psi$-I curves with and without magnets, it is clear that the PM assist has increased the enclosed area considerably as shown in Fig. 10, and therefore this will have a positive effect on torque capability.

It is clear that the PM assist machine has a high unaligned flux linkage at high current. This is due to the delay in saturation due to the reverse bias effect of the magnets. Saturation is also significantly slowed in the aligned position, as show in the aligned $\Psi$-I gradient when comparing the magnet assist and magnet free curves.

\section{B. Torque comparison}

The torque capability of the prototype machine was then measured on a static torque test rig, again this was carried out with and without PM assist. In this test one of the two fault tolerant lanes are energized. Fig. 11 shows the average torque over the operating range, whilst Fig. 12 shows the torque at 11 amps (the rated peak current) and over a full electrical cycle. Clearly the design procedure is verified with a close experimental and simulated set of results. With the PM assist the average torque is confirmed to increase by $28 \%$.

There is a clear shift in the angular location of the peak torque position with PM assist, as shown in Fig. 12 This has been taken account of during the dynamic tests with the appropriate phase advance set to maximize torque.

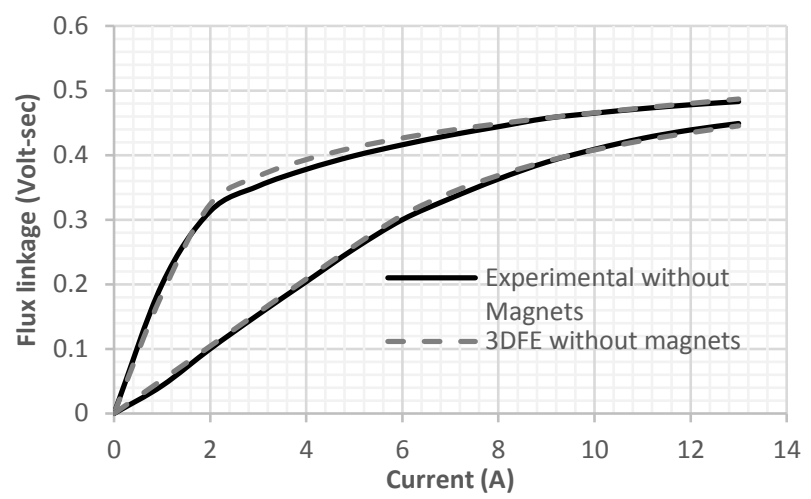

Fig. 9. Experimental and 3DFE flux linkage current waveforms without PM assist.

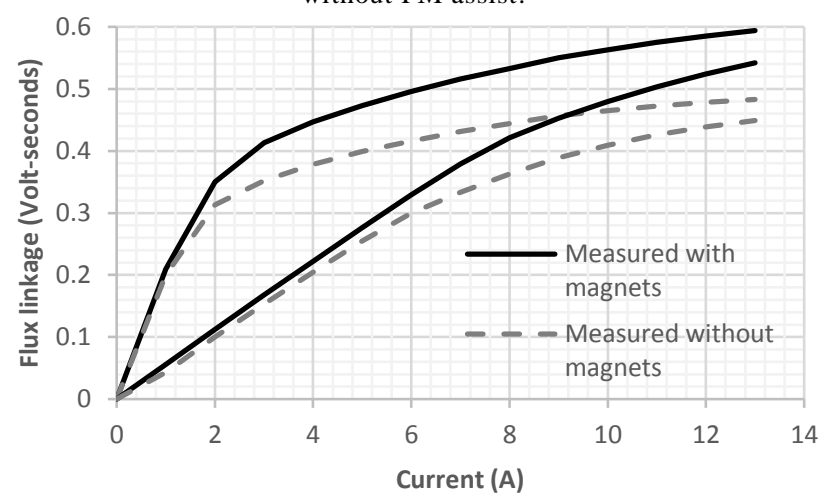

Fig. 10. Measured flux linkage curves of the prototype machine both

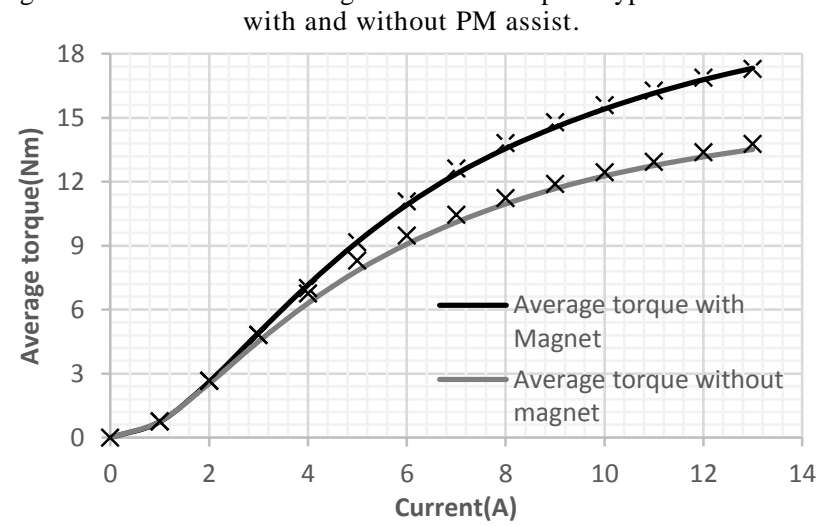

Fig. 11. Average measured torque (solid line) with and without magnets and comparison with the 3DFE models (marked with $\mathrm{X}$ ).

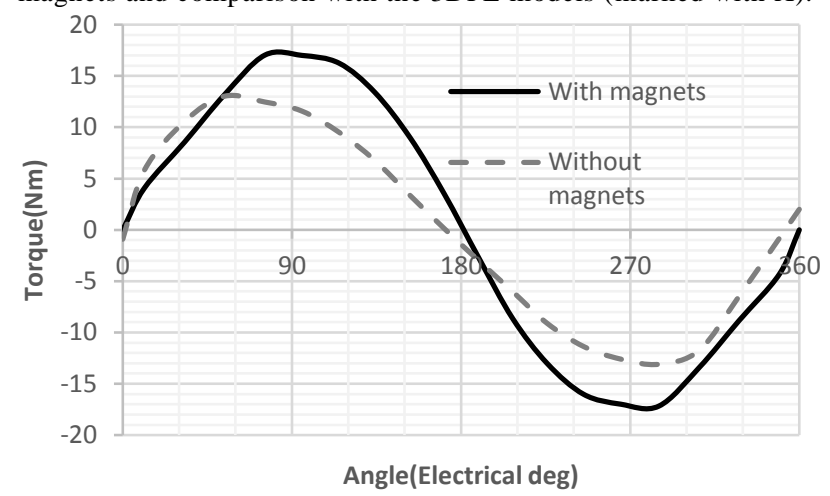

Fig. 12. Measured torque over a full electrical cycle at rated current with and without PM assist. 


\section{DYNAMIC TESTING}

During dynamic testing the prototype machine was coupled via a torque transducer to an induction machine acting as a load. The prototype machine was driven using a bespoke threephase asymmetric half bridge supplied with $480 \mathrm{~V} \mathrm{DC}$ and switching at $20 \mathrm{KHz}$. Fig. 13 shows the test rig

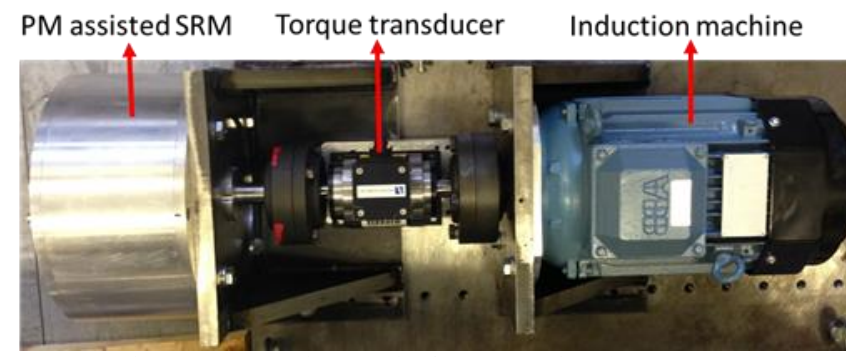

Fig. 13. Dynamic test rig for PM assisted S-SRM

The machine was run from standstill to $900 \mathrm{rpm}$ and torque measured at phase currents up to $11 \mathrm{~A}$. At $900 \mathrm{rpm}$, the turnon angle was advanced to obtain maximum torque. Once again tests were carried out with and without PM assist.

Table 2 shows the machine performance at $100 \mathrm{rpm}$, whilst Table 3 shows the performance at $900 \mathrm{rpm}$. System efficiency includes the machine and drive input and the mechanical power output. Fig. 14 and Fig. 15 shows the current waveforms of PM assisted SRM with and without magnets at $900 \mathrm{rpm}$ with 180 degree conduction respectively.

Table 2: Prototype machine performance with and without magnets $\left(180^{\circ}\right.$ conduction angle, minimal advance, $\left.100 \mathrm{rpm}\right)$

\begin{tabular}{|c|c|c|}
\hline Measurements & Without PM assist & With PM assist \\
\hline Speed & $111 \mathrm{rpm}$ & $111 \mathrm{rpm}$ \\
\hline Torque & $12.8 \mathrm{Nm}$ & $16 \mathrm{Nm}$ \\
\hline RMS current & $7.39 \mathrm{~A}$ & $7.31 \mathrm{~A}$ \\
\hline $\begin{array}{c}\text { Input power } \\
\text { Current advance } \\
\text { angle }\end{array}$ & $884 \mathrm{~W}$ & $1016 \mathrm{~W}$ \\
\hline $\begin{array}{c}\text { Conducting angle } \\
\text { Output power }\end{array}$ & $180^{\circ}$ & $180^{\circ}$ \\
\hline Efficiency & $148.54 \mathrm{~W}$ & $198.9 \mathrm{~W}$ \\
\hline
\end{tabular}

\section{MASS COMPARISON WITH THE BASELINE PM MACHINE}

PM machines are highly suitable for aerospace applications because of their high torque density. Fault tolerance is however an issue which needs special mitigation.

Fig. 16 compares the mass of the PM assisted segmental rotor SRM with that of the baseline PM machine. Although the overall machine masses are similar, the PM assisted segmental rotor SRM uses only $32 \%$ of the magnet mass of the baseline PM machine.
Table 3: Efficiency of the prototype with and without magnets with $180 \mathrm{deg}$ electrical conduction at $900 \mathrm{rpm}$.

\begin{tabular}{|l|l|l|}
\hline Measurements & Without PM assist & With PM assist \\
\hline Speed & $908 \mathrm{rpm}$ & $920 \mathrm{rpm}$ \\
\hline Torque & $10.3 \mathrm{Nm}$ & $12.5 \mathrm{Nm}$ \\
\hline RMS current & $5.25 \mathrm{~A}$ & $5.03 \mathrm{~A}$ \\
\hline Input power & $1499 \mathrm{~W}$ & $1773 \mathrm{~W}$ \\
\hline Current advance angle & $40^{\circ}$ & $40^{\circ}$ \\
\hline Conducting angle & $180^{\circ}$ & $180^{\circ}$ \\
\hline Output power & $979.3 \mathrm{~W}$ & $1204.3 \mathrm{~W}$ \\
\hline Efficiency & $65.3 \%$ & $67.9 \%$ \\
\hline
\end{tabular}

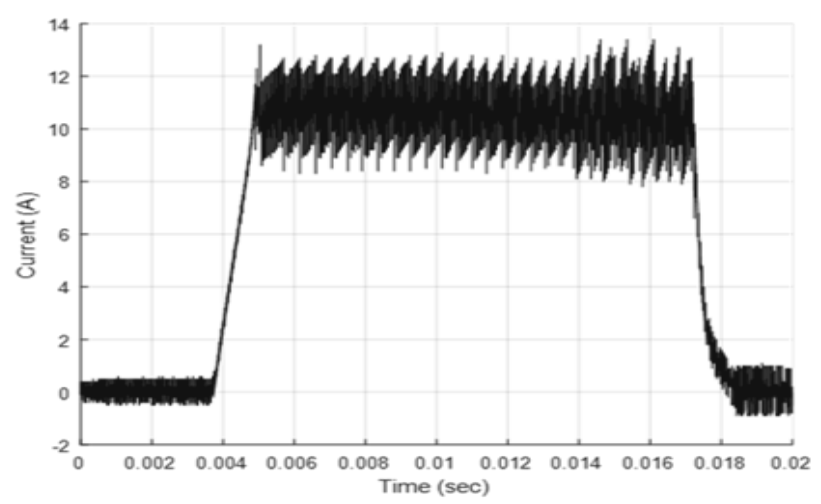

Fig. 14. Current waveform at 100 rpm with PM assist.

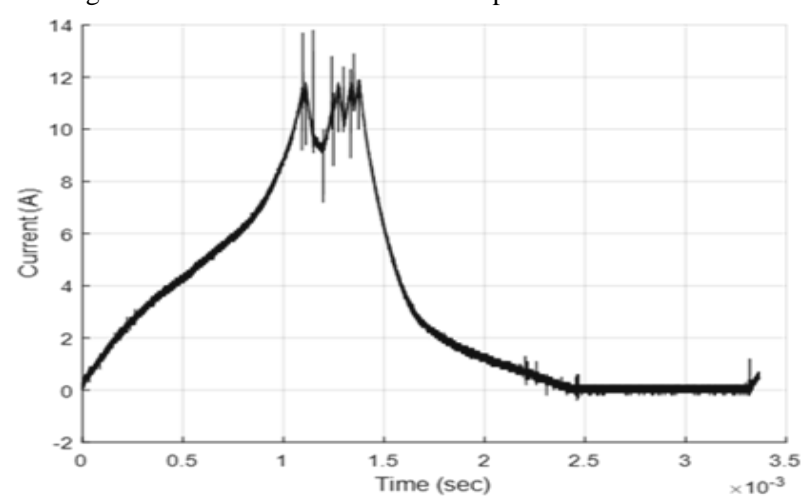

Fig. 15. Current waveform at $900 \mathrm{rpm}$ with PM assist.

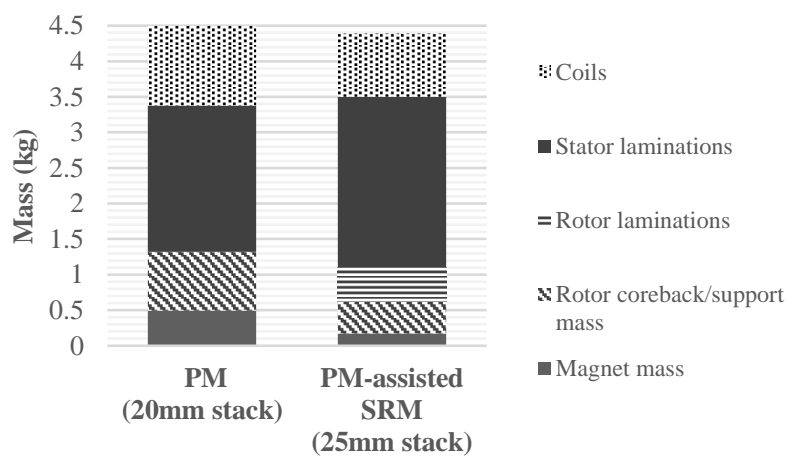

Fig. 16. Mass comparison of the baseline PM machine and the new PM assist S-SRM. 


\section{FAUlt TOLERANT PERFORMANCE}

Much effort goes into the design of a fault tolerant drive to ensure magnetic, thermal and electrical isolation between phases and power lanes. Where torque density is of importance, as is the case for an aerospace application, PMSMs have generally been the machine of choice.

PMSMs do however induce large back EMFs in the phases, which can be a significant concern under open circuit, and especially short circuit faulted conditions. Much effort goes into designing a 1-per-unit reactance to limit any short circuit current to within the thermal capability of the machine.

In the PMA S-SRM the rotational induced EMFs are minimal. The magnets, placed on the stator, experience a slight perturbation in their operating point as the rotor rotates and the reluctance of the magnetic path alternates. The measurements shown here highlight that this is a small fraction of that in a fault tolerant PMSM.

\section{A. Open circuit fault}

In a fault tolerant application the open circuit fault is one of the more benign conditions. Consideration is needed to ensure the induced EMF does not drive circulating currents within the electrical drive at all operational speeds. Where field weakening is applied an open circuit fault on a PMSM has the potential to impose an EMF several times the rating of the devices with a catastrophic outcome where safety is critical. This is not the case in the PMA S-SRM, where the open circuit induced voltage is due to slight changes in the magnet operating point. At the maximum speed of 900rpm a peak EMF of $5.2 \mathrm{~V}$ is measured, Fig. 17. This compares to $270 \mathrm{~V}$ for the PMSM and highlights the improved fault tolerance of the PMA S-SRM in this safety critical application.

\section{B. Short circuit fault}

During a phase short circuit fault the EMF drives a short circuit fault current. This in turn imposes a drag torque on the rotor, which the remaining healthy phases must overcome to maintain full torque output in a safety critical application.
For the PMSM, the machine is designed to have 1-per -unit reactance, thus limiting the short circuit fault current to 1-perunit, and thereby maintaining thermal stability during the fault. For the PMA S-SRM, the minimal EMF results in a minimal short circuit fault current. Driving the machine at 900rpm using power lane 1 and imposing a short circuit fault on Phase A of lane 2 results in the measured short circuit current shown in Fig. 18. This $42 \mathrm{~mA}_{\mathrm{rms}}$ fault current compares to $25 \mathrm{~A}_{\mathrm{rms}}$ for the PMSM. Once again the fault tolerant capability of this drive topology is highlighted.

\section{Comparison of torque density and fault tolerance.}

It has been shown that the torque density of a segmented rotor SRM can be over $40 \%$ greater than a standard rotor SRM (for equal volume and temperature rise) [4]. Separately it has been shown that permanent magnet assist increases the torque density of a standard rotor SRM by $26 \%$ [8]. In both examples the machines can exhibit magnetic isolation if the winding arrangement is altered as described by Radun [24], however full fault tolerance (magnetic + electric + thermal isolation between lanes) is not possible without a significant re-design. Ullah et al $[9,16,25]$ directly compare dual lane arrangements of SRM (Single lane, duplex), SRM (with spacer teeth), SSRM and PMSM. All machines have the same space envelope, current density and current waveforms and meet the fault tolerance requirement of full isolation between lanes.

The Segmented rotor SRM is shown to have 23\% greater torque density over the standard rotor SRM within the same volume and temperature rise.

A further comparison is made $[23,25]$ between the dual lane SSRM and the same with PM assist. An additional $25 \%$ of torque is gained, a result consistent with [8]. Table 4 summarizes and compares these results.

Therefore one may conclude that for fault tolerant applications where dual lanes are required, the compound effect of the segmented rotor plus permanent magnet assist applied to the SRM offers a torque density comparable with a dual lane PMSM and at a greater level of fault tolerance. Such a finding will be of great interest to drive applications where safety is critical.

Table 4. Torque density and fault tolerant capability comparison gathered from several studies.

\begin{tabular}{|c|c|c|c|c|c|c|}
\hline \multirow{2}{*}{ Motor Type } & \multirow{2}{*}{ Ref. } & \multicolumn{2}{|c|}{ Torque output } & \multicolumn{3}{|c|}{ Fault tolerant capability } \\
\hline & & Torque $(\mathrm{Nm})$ & Per Unit comparison & Magnetic & Electrical & Thermal \\
\hline \multicolumn{7}{|c|}{ SRM -v- Segmented rotor SRM (Single lane) } \\
\hline Single lane SRM & [4] & 22.5 & 1.0 & YES [24] & $\mathrm{NO}$ & $\mathrm{NO}$ \\
\hline Segmented rotor SRM & {$[4]$} & 32.0 & 1.44 & YES [24] & $\mathrm{NO}$ & $\mathrm{NO}$ \\
\hline PMSM & [4] & 42.0 & 1.87 & & & \\
\hline \multicolumn{7}{|c|}{ SRM -v- PM assist SRM (Single lane) } \\
\hline Single lane SRM without PM Assist & [8] & 3.8 & 1.0 & YES [24] & NO & NO \\
\hline Single lane SRM with PM assist & [8] & 4.8 & 1.26 & YES [24] & NO & NO \\
\hline \multicolumn{7}{|c|}{ PMSM -v- SRM -v- Segmented rotor SRM (Dual lane) } \\
\hline Single lane SRM (duplex arrangement) & {$[9,16,25]$} & 1.47 & 1.0 & YES & YES & YES \\
\hline Dual lane SRM (with spacer teeth) & {$[9,16,25]$} & 1.10 & 0.75 & YES & YES & YES \\
\hline Dual lane S-SRM & {$[9,16,25]$} & 1.82 & 1.23 & YES & YES & YES \\
\hline Dual lane PMSM & {$[9,16,25]$} & 1.86 & 1.27 & YES & YES & YES \\
\hline \multicolumn{7}{|c|}{ Segmented rotor SRM -v- Segmented rotor SRM with PM assist (Dual lane) } \\
\hline Dual lane S-SRM without PM Assist & {$[23,25]$} & 12.8 & 1.0 & YES & YES & YES \\
\hline Dual lane S-SRM with PM Assist & {$[23,25]$} & 16.0 & 1.25 & YES & YES & YES \\
\hline
\end{tabular}




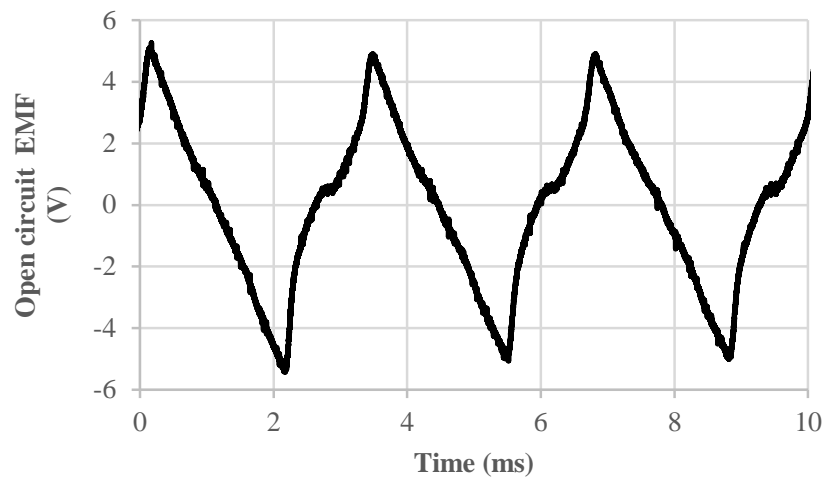

Fig. 17. Phase open circuit fault - measured phase EMF at 900rpm.

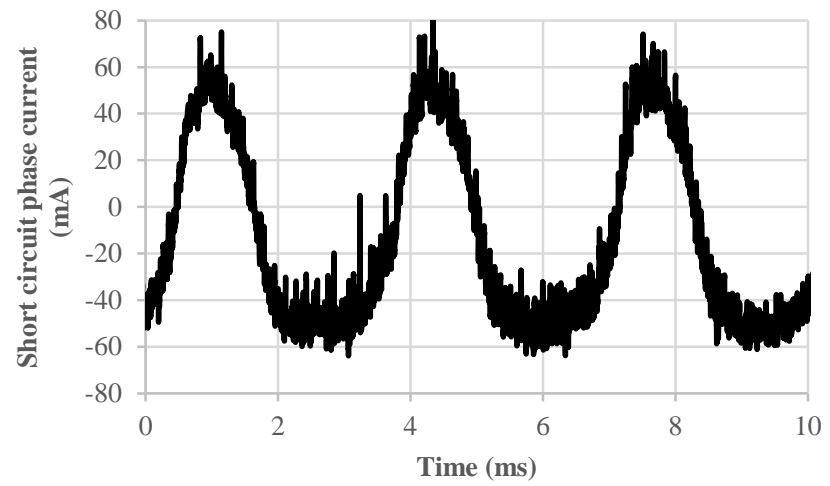

Fig. 18. Phase short circuit fault - measured phase current at 900rpm

\section{CONCLUSION}

A permanent magnet assist concept has been applied to a fault tolerant, segmented rotor SRM. This PMA S-SRM has been constructed and tested and shown to be a strong contender for aerospace applications due to its comparable torque density and enhanced fault tolerance when compared to a fault tolerant PMSM.

The benefit of the permanent magnet bias applied to the segmented rotor SRM was demonstrated first using 3DFE, where in increase in torque of $21 \%$ was predicted compared to the magnet free S-SRM. Laboratory testing of the prototype machine both with and without magnets confirmed this result. Dynamic testing of the machine was done at two critical speeds, and the desired specification met. Future development will however need to concentrate in increasing the efficiency of this topology.

With the magnets removed from the rotor and a smaller amount placed on the stator, rotational induced EMFs are vastly reduced, as is the associated short circuit current, now only $41 \mathrm{~mA}_{\text {rms. }}$. Hence the fault tolerance capability of this drive topology is a great improvement over a PMSM where full rated current and voltage must be managed during a fault. As the mass of this machine matched its PMSM counterpart, the authors believe this fault tolerant PM Assist Segmented Rotor SRM topology offers a real alternative in safety critical applications and will be of great interest to engineers working in this area.

\section{ACKNOWLEDGMENT}

The authors would like to acknowledge the funding provided for this work from the European Actuation 2015 collaborative research and development project coordinated by Goodrich Actuation Systems SAS, and UTC: www.actuation2015.eu

\section{REFERENCES}

R. Krishnan, Switched Reluctance Motor Drives: Industrial Electronics Series, CRC Press 2001

T. Raminosoa, A. M. El-Refaie, D. A. Torrey, K. Grace, D. Pan, S. Grubic, K. Bodla, and K. K. Huh, "Test Results for a High Temperature Non-Permanent-Magnet Traction Motor," IEEE Transactions on Industry Applications, vol. 53, no. 4, pp. 34963504, 2017.

B. C. Mecrow, E. A. El-Kharashi, J. W. Finch, and A. G. Jack, "Segmental rotor switched reluctance motors with single-tooth windings," IEE Proceedings - Electric Power Applications, vol. 150, no. 5, pp. 591-599, 2003.

B. C. Mecrow, E. A. El-Kharashi, J. W. Finch, and A. G. Jack, "Preliminary performance evaluation of switched reluctance motors with segmental rotors," IEEE Transactions on Energy Conversion, vol. 19, no. 4, pp. 679-686, 2004.

Y. Hasegawa, K. Nakamura, and O. Ichinokura, "Basic consideration of switched reluctance motor with auxiliary windings and permanent magnets." pp. 92-97.

L. Yuefeng, L. Feng, and T. A. Lipo, "A novel permanent magnet motor with doubly salient structure," IEEE Transactions on Industry Applications, vol. 31, no. 5, pp. 1069-1078, 1995.

P. Andrada, B. Blanqué, E. Martínez, and M. Torrent, "New hybrid reluctance motor drive." pp. 2689-2694.

N. Kenji, M. Kohei, and I. Osamu, "Characteristics of a novel switched reluctance motor having permanent magnets between the stator pole-tips." pp. 1-5.

D. Smith "ACTUATION 2015: Fault Tolerant Architecture Findings" November 2012 available via http://www.actuation2015.eu/.

B. Sarlioglu, and C. T. Morris, "More Electric Aircraft: Review, Challenges, and Opportunities for Commercial Transport Aircraft," IEEE Transactions on Transportation Electrification, vol. 1, no. 1, pp. 54-64, 2015.

M. Villani, M. Tursini, G. Fabri, and L. Castellini, "Electromechanical Actuator for Helicopter Rotor Damper Application," IEEE Transactions on Industry Applications, vol. 50, no. 2, pp. 1007-1014, 2014. G. Madhu, and G. R. Bindu, "A Novel Slotless Halbach-Array Permanent-Magnet Brushless DC Motor for Spacecraft Applications," IEEE Transactions on Industrial Electronics, vol. 59, no. 9, pp. 3553-3560, 2012.

M. E. Beniakar, A. G. Sarigiannidis, P. E. Kakosimos, and A. G. Kladas, "Multiobjective Evolutionary Optimization of a Surface Mounted PM Actuator With Fractional Slot Winding for Aerospace Applications," IEEE Transactions on Magnetics, vol. 50, no. 2, pp. 665-668, 2014.

A. G. Sarigiannidis, M. E. Beniakar, P. E. Kakosimos, and A. G. Kladas, "Multi-operating points PM motor design methodology for electric actuation systems." pp. 2506-2512.

A. G. Sarigiannidis, M. E. Beniakar, P. E. Kakosimos, A. G. Kladas, L. Papini, and C. Gerada, "Fault Tolerant Design of Fractional Slot Winding Permanent Magnet Aerospace Actuator," IEEE Transactions on Transportation Electrification, vol. 2, no. 3, pp. 380-390, 2016.

S. P. McDonald, G. J. Atkinson, D. J. B. Smith, and S. Ullah, "Overcoming the challenges of "drag torque" in a dual-lane actuator for an aircraft." pp. 2120-2126. ICEM 2014 "Fault-Tolerant Design Considerations and Control Strategies for Aerospace Drives," IEEE Transactions on Industrial Electronics, vol. 59, no. 5, pp. 2049-2058, 2012. 
[18] H. Guo, J. Xu, and Y. H. Chen, "Robust Control of Fault-Tolerant Permanent-Magnet Synchronous Motor for Aerospace Application With Guaranteed Fault Switch Process," IEEE Transactions on Industrial Electronics, vol. 62, no. 12, pp. 7309-7321, 2015.

[19] P. Arumugam, T. Hamiti, C. Brunson, and C. Gerada, "Analysis of Vertical Strip Wound Fault-Tolerant Permanent Magnet Synchronous Machines," IEEE Transactions on Industrial Electronics, vol. 61, no. 3, pp. 1158-1168, 2014.

[20] L. Papini, T. Raminosoa, D. Gerada, and C. Gerada, "A HighSpeed Permanent-Magnet Machine for Fault-Tolerant Drivetrains," IEEE Transactions on Industrial Electronics, vol. 61, no. 6, pp. 3071-3080, 2014.

[21] J. B. Bartolo, M. Degano, J. Espina, and C. Gerada, "Design and Initial Testing of a High-Speed 45-kW Switched Reluctance Drive for Aerospace Application," IEEE Transactions on Industrial Electronics, vol. 64, no. 2, pp. 988-997, 2017.

[22] J. W. Bennett, B. C. Mecrow, D. J. Atkinson, C. Maxwell, and M. Benarous, "Fault-tolerant electric drive for an aircraft nose wheel steering actuator," IET Electrical Systems in Transportation, vol. 1, no. 3, pp. 117-125, 2011

[23] S. Ullah, S. P. McDonald, R. Martin, and G. J. Atkinson, "A permanent magnet assisted switched reluctance machine for more electric aircraft." pp. 79-85. ICEM 2016

[24] A.V.Radun,C.A.Ferreira,E.Richter "two Channel Switched Reluctance Starter/Generator Results" IEEE Transactions on Industry Applications, vol. 34, Issue: 5, 1998, pp 1026-1034

[25] Sana. Ullah "A magnet assisted segmental rotor switched reluctance machine suitable for fault tolerant aerospace applications" Newcastle University PhD Thesis, 2016. 